\title{
Particle-Associated PAHs in Urban and Rural Ambient Air Samples
}

\author{
Andrea Szabó Nagy, János Szabó \\ Physics and Chemistry Department, Széchenyi István University \\ Egyetem square 1, Györ, Hungary \\ nszaboa@sze.hu; jszabo@sze.hu
}

\begin{abstract}
The purpose of this study was to evaluate and compare the concentration levels and distributions of airborne polycyclic aromatic hydrocarbons (PAHs) between urban area of Győr and the nearest rural area of Sarród (Hungary). Nineteen selected polycyclic aromatic hydrocarbons (PAHs) including the 16 priority US EPA PAH compounds, 2-methylnaphthalene, benzo(j)fluoranthene and benzo(e)pyrene in PM10 aerosol samples were determined under the authority of the Government Office for Györ-Moson-Sopron County, Environmental Protection Laboratory and seasonal distributions were examined based on long-term monitoring data. Moreover, the concentration levels of fine (PM2.5) particle-associated PAHs measured in Györ in a heating season are also discussed. About 2 times higher Total PAHs concentrations were obtained for urban samples compared to the rural samples on average. All of the investigated PAH compounds were identified in the PM10 aerosol samples. PAHs fluctuate significantly in all years with higher means and peak concentrations in the winter and autumn compared to that of spring or summer times at both monitoring sites. Approximately 27 and 18 times higher benzo(a)pyrene (BaP) toxic equivalence quotient (TEQ) concentrations in PM10 in urban and rural sites were detected in the heating seasons, respectively. Acenaphthene and fluorene were not detected in the PM2.5 samples. The dominant PM2.5-bound PAH compounds were indeno(1,2,3-cd)pyrene and sum of three benzofluoranthene isomers followed by benzo(ghi)perylene and BaP. Relatively high mean TEQ concentration level were observed for PM2.5-bound PAHs in the examined heating season.
\end{abstract}

Keywords: Urban Rural Comparison, PAH, Monitoring, PM10, PM2.5.

\section{Introduction}

Polycyclic aromatic hydrocarbons (PAHs) are ubiquitous organic compounds in the ambient air. They are composed of two or more fused benzene rings and emitted into the atmosphere after incomplete combustion of organic material and evaporation of PAH containing fossil fuels. PAHs are a concern due to their carcinogenicity and propensity for transboundary atmospheric transport. Generally, in urban areas traffic is a dominant source, while in rural area wood burning can be dominant. However, sources of PAHs in urban atmosphere also include power plants, refineries and resuspended soils [1]. Additional contributions to ambient air levels arise from heating sources, road dust and tobacco smoking. Natural sources such as forest fires and volcanic eruptions are less important [2]. The composition of PAHs in these emissions depends on many factors, such as the type of fuel as well as combustion efficiencies. Moreover, once emitted into the atmosphere, the atmospheric lifetime of PAHs is influenced by many factors, such as photo-chemical oxidation and meteorological conditions.

PAHs exist in the atmosphere in both vapor and particulate phase. The particle-associated PAHs are more harmful to human health because they are inhalable and ingestible and can deposit in the human respiratory system. The analysis of atmospheric particles with an aerodynamic diameter $<10 \mu \mathrm{m}$ (PM10) or less (e.g. PM2.5) from urban regions has become important, considering the biological effects and potential health hazards they can impose [3]. The US Environmental Protection Agency (EPA) has identified 16 unsubstituted PAHs as priority pollutants for measurement in environmental samples [4]. The US EPA PAHs are commonly classified into one of three groups based on their molecular structure. Low molecular weight (LMW) PAHs have two or three aromatic rings, intermediate molecular weight (MMW) PAHs have four rings, while high molecular weight (HMW) PAHs have five or six rings. Differences in the structure and size of individual PAHs result in substantial variability in the physical and chemical properties of these substances. Generally, most of the 16 EPA PAHs (or a subset of these) are targeted in the current monitoring of air and air pollution studies.

One of the best characterized and most toxic PAH compound is benzo(a)pyrene (BaP), which is generally used as the indicator PAH. A recent study [5] on BaP in Europe have revealed that the population exposure estimate shows that $20 \%$ 
of the European population is exposed to BaP background ambient concentrations above the EU annual mean target value $\left(1 \mathrm{ng} / \mathrm{m}^{3}\right)$ and only $7 \%$ live in areas with concentrations under the estimated acceptable risk level of $0.12 \mathrm{ng} / \mathrm{m}^{3}$ recommended by the World Health Organisation (WHO). Emissions of BaP have increased in the last decade with the increase in emissions from household combustion of biomass.

In Hungary, the nationwide monitoring of PM10-bound PAHs in ambient air is importance for numbers of reasons related to human health, the environment and compliance with European Union legislation. However, the measurement of PAH concentrations in PM2.5 aerosol fraction has not been carried out. Within the framework of the Hungarian PM10 Monitoring Program, the PM10 samples that are analysed for the PAHs (BaP, benzo(a)anthracene, three benzofluoranthene $(\mathrm{BF})$ isomers $(\mathrm{b}, \mathrm{k}$ and $\mathrm{j})$, indeno(1,2,3-cd)pyrene (IND) and dibenzo(a,h)anthracene) are collected on a 24-hour basis, for 2 weeks in four periods a year [6]. A part of the measured data is registered in the European air quality database maintained by the European Environment Agency.

In this study, an urban and rural comparison of 19 PAH compound (16 priority US EPA PAHs, 2methylnaphthalene (mNAP), benzo(j)fluoranthene $(\mathrm{BjF})$ and benzo(e)pyrene $(\mathrm{BeP})$ ) concentrations in PM10 aerosol samples were evaluated from the long-term monitoring data of urban site of Györ and the rural site of Sarród (Hungary). The data were measured by the Government Office for Györ-Moson-Sopron County, Environmental Protection Laboratory under the Hungarian Monitoring Network. Additionally, PM2.5 samples for PAH analysis were also collected in urban area of Györ in a heating season supported by the Széchenyi István University.

\section{Material and Methods}

\subsection{Study Area and PM Sampling}

Györ is the most important city in northwest Hungary, the capital of Györ-Moson-Sopron County and one of the seven main regional centres of the country. It has become one of the largest economic, industrial and traffic areas of Hungary. The geographical location of city is $47^{\circ} 41^{\prime} 02^{\prime \prime} \mathrm{N}, 17^{\circ} 38^{\prime} 06^{\prime \prime} \mathrm{E}$ and has an urban population of 130,000 . There are two permanent air monitoring stations in Győr [7]. The PM10 sampling was carried out only at one monitoring site (U1) located approximately $3 \mathrm{~km}$ south of the city centre from the year 2008. It was originally classified as an urban background, but nowadays it can be considered to become an urban traffic site. PM2.5 aerosol samples were collected for two weeks at both monitoring sites in the heating season in the year 2014. The other urban traffic site (U2) is located along one of the busiest roads in the centre of the city near the bus and train main stations.

Sarród is situated in the northwest part of Hungary near to the border between Austria and Hungary, in the FertöHanság National Park. The sampling site located in a rural environment, without significant traffic and industrial activities, but influenced by human sources from agriculture and combustion.

The PM samples were collected on quartz fibre filters with a diameter of $150 \mathrm{~mm}$ over a 24-hour. High volume aerosol samplers (Digitel DHA-80, Digitel Elektronik AG, Switzerland) equipped with PM10 or PM2.5 inlets were used at flow rate of $30 \mathrm{~m}^{3} / \mathrm{h}$. The samplers were loaded with 14 filters, which were changed automatically every 24 hours at midnight. Before and after sampling, the filters were conditioned for $48 \mathrm{~h}$ at $20 \pm 1{ }^{\circ} \mathrm{C}$ and $50 \pm 5 \%$ relative humidity. The particle total mass was determined by weighing of the sampling filters before and after sampling and the PM concentration calculated from the weighed mass on the filter and the sampling volume. The filters were wrapped in aluminium foil separately and stored in a refrigerator at $4{ }^{\circ} \mathrm{C}$ until chemical analysis [8].

\subsection{PAH Analysis}

The ultrasonic liquid-solid extraction of the filter sample and the PAH analysis were conducted in accordance with the Hungarian standard method procedure [9]. A gas chromatography-mass selective detector (GC-MSD) system consisting of an Agilent $6890 \mathrm{GC}$ (Palo Alto, CA, USA) with an Rtx-5MS Integra GC column (30 m long, $0.25 \mathrm{~mm}$ internal diameter, $0.25 \mu \mathrm{m}$ coating, $5 \%$ diphenyl - $95 \%$ dimethyl polysiloxane; Restek Bellefonte, PA, USA) and an Agilent 5973 MSD was used in the study. The method was described in detail in our previous work [8]. The limit of detection was about $0.02 \mathrm{ng} / \mathrm{m}^{3}$. The 16 US EPA PAHs and mNAP were monitored in the period of 2008-2009 and $\mathrm{BjF}$ was added to the measurement compound list in 2010. Since the year 2011, BeP has also been determined. The Total PAHs concentration was calculated as the sum of the concentrations of determined PAH species for each collected sample. 


\subsection{BaP-equivalent Concentrations and Lifetime Lung Cancer Risk (LCR)}

One method of risk assessment would be to assume that the toxicity of all the PAHs is equivalent to that of $\mathrm{BaP}$. Several available data have evaluated on the carcinogenic potency of different PAHs and developed toxicity equivalency factors (TEFs) for the individual PAHs [10]. These TEFs indicate the carcinogenic potency of each compound relative to $\mathrm{BaP}$, and multiplying the concentration of each PAH by the TEF yields a concentration for the total PAH mixture that is expressed in terms of an equivalent concentration (with regarding to toxic potency) of $\mathrm{BaP}$. The BaP toxic equivalence quotient (TEQ) based on number of contributing compounds in the sample can be calculated with Eq. (1).

$$
\mathrm{TEQ}=\Sigma \mathrm{Ci} \cdot \mathrm{TEFi}
$$

where, $\mathrm{C}_{\mathrm{i}}$ and $\mathrm{TEF}_{\mathrm{i}}$ are the concentration and toxicity equivalency factor of individual PAH compounds, respectively.

In this study, the WHO Toxic Equivalence Factors for PAHs are used [11] (Table 1). Based on WHO data, the unit risk (UR) for PAHs, indicated the estimated lifetime lung cancer risk (LCR) from exposure to atmospheric PAHs, is $8.7 \times$ $10^{-5}$ (i.e., incidence of 8-7 cases per 100000 people with chronic inhalation exposure to $1 \mathrm{ng} / \mathrm{m}^{3}$ BaP over a lifetime of 70 years [12]. The LCR attributable to PAHs inhalation exposure was estimated by using Eq. (2).

$$
\mathrm{LCR}=\mathrm{UR} \cdot \mathrm{TEQ}
$$

Table 1: World Health Organisation Toxic Equivalence Factors for PAHs.

\begin{tabular}{|c|c|}
\hline PAH compound & TEF \\
\hline Benzo(a)anthracene & 0.1 \\
\hline Benzo(a)pyrene & 1 \\
\hline Benzo(b-j)fluoranthene & 0.1 \\
\hline Benzo(k)fluoranthene & 0.1 \\
\hline Benzo(ghi)perylene & 0.01 \\
\hline Chrysene & 0.01 \\
\hline Dibenzo(a,h)anthracene & 1 \\
\hline Indeno(1,2,3-cd)pyrene & 0.1 \\
\hline
\end{tabular}

\section{Results and Discussions}

\subsection{Concentrations and Seasonally Variations of PAHs in Urban and Rural PM10 Aerosol Samples}

The annual mean and maximum concentrations of PM10 and associated Total PAHs in urban site of Györ compared to rural site of Sarród are illustrated in Fig. 1. On average, about 2 times higher concentrations were obtained for urban samples compared to the rural samples. The Total PAHs mass concentrations for the 7-year sampling period were 0.0795.8 and $0.02-40.6 \mathrm{ng} / \mathrm{m}^{3}$, with a mean of 11.6 and $5.8 \mathrm{ng} / \mathrm{m}^{3}$ in urban and rural sites, respectively. The percentage contribution of Total PAHs to PM10 concentrations is shown in Fig. 2. On average, the Total PAHs accounted for about 0.034 and $0.031 \%$ of the PM10 mass.

Strong monthly trends were observed for both individual compounds and the Total PAHs concentrations at both sites (Figs. 3-4). The results based on seasonally distributions suggested that the particle-bound PAH concentrations varied inversely with temperature: i.e., higher concentrations in the cold months and lower ones in the warm months. The increase in particulate $\mathrm{PAH}$ concentration during the winter and the dependence of PAH concentration on atmospheric temperature have been reported in a number of previously published studies [1] and [13]. All of the priority 16 US EPA PAH compounds, mNAP, and BjF were identified in the PM10 samples (Fig. 4). The MMW and HMW PAHs were the most abundant compounds in PM10 in winter, spring and autumn. However, it was found that the LMW PAHs had a higher contribution in summer. 


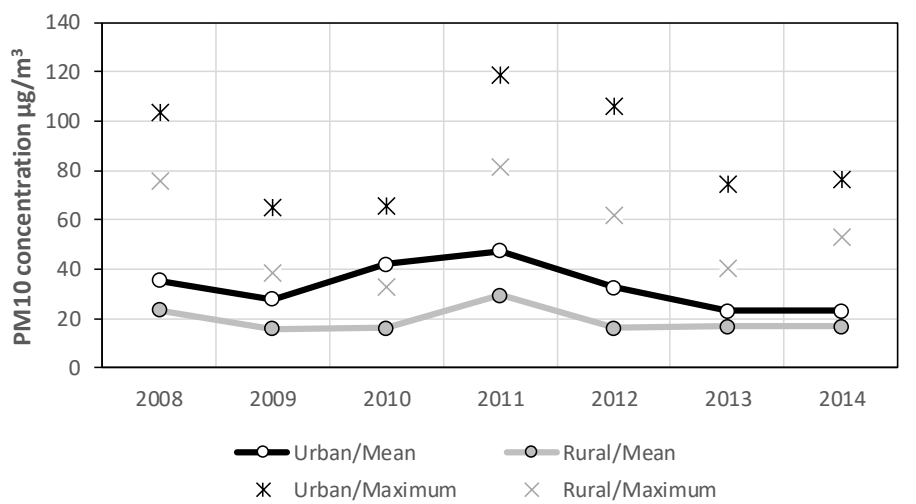

a,

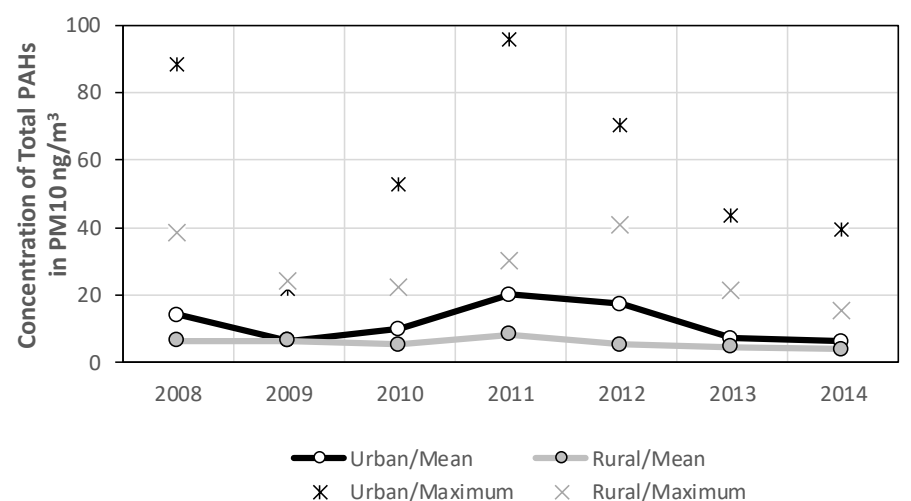

b,

Fig. 1: Annual mean and maximum concentrations of PM10 and associated Total PAHs in urban site of Győr compared to rural site of Sarród.

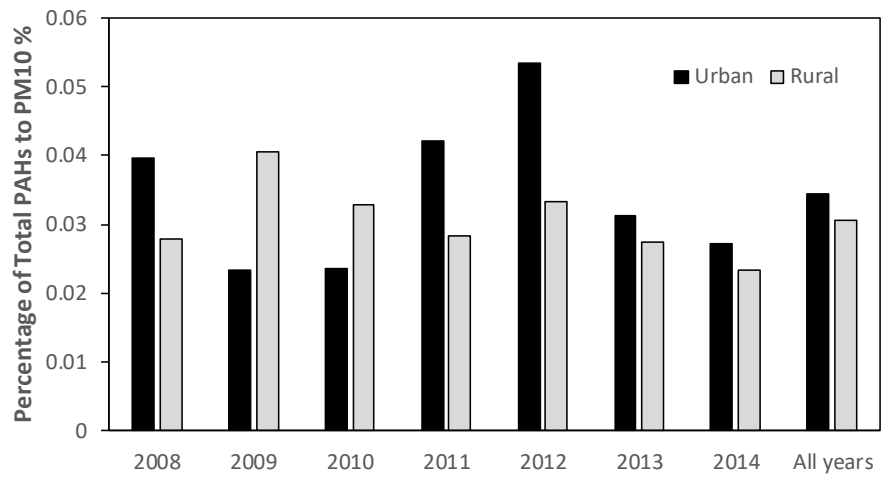

Fig. 2: Percentage contribution of Total PAHs to PM10 concentrations in urban site of Györ compared to rural site of Sarród.

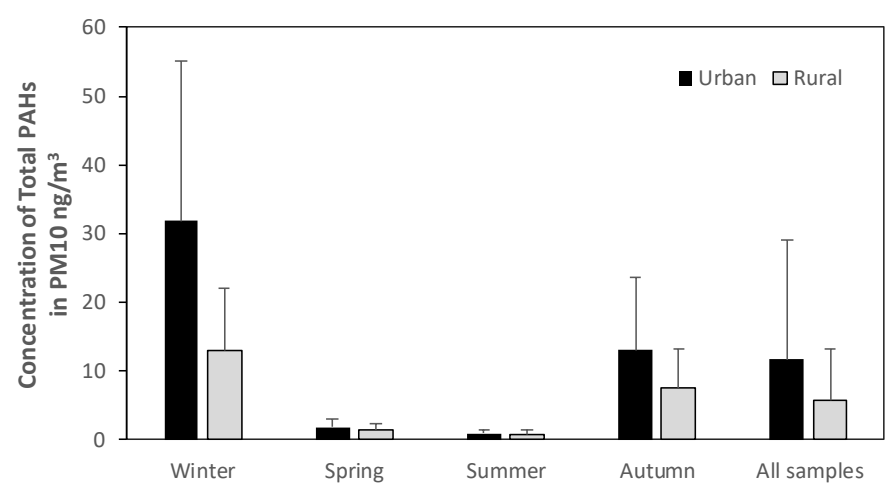

a,

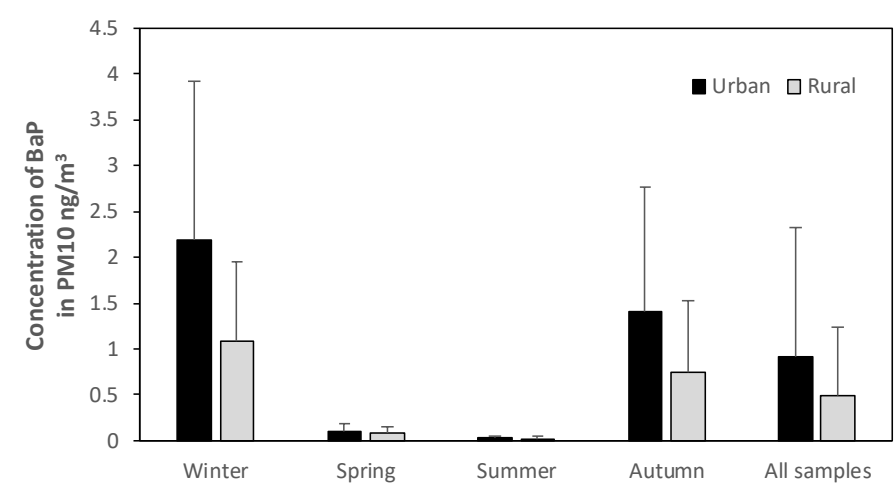

b,

Fig. 3: Seasonally distributions of Total PAHs and BaP in urban site of Györ compared to rural site of Sarród based on data of all examined samples.

Moreover, several factors may contribute to the strong seasonal trend [1] and [13]. Reduced atmospheric dispersion resulting from lower mixing height as well as reduced atmospheric reaction can lead to higher pollutant concentrations in ambient air during winter. Low atmospheric temperature can affect the distribution of PAHs between the gas and particle phases and result in a relatively larger portion of PAH partitioning to the particle phase. In addition to temperature effects on the physio-chemical property of atmospheric PAHs, anthropogenic factors can also 
lead to seasonal variation of particulate PAHs. During the cold season, PAH emissions from automobile exhaust are higher because of low ambient temperature and increased cold start impacts. Domestic heating is also likely to contribute to elevated PAH emissions in winter.

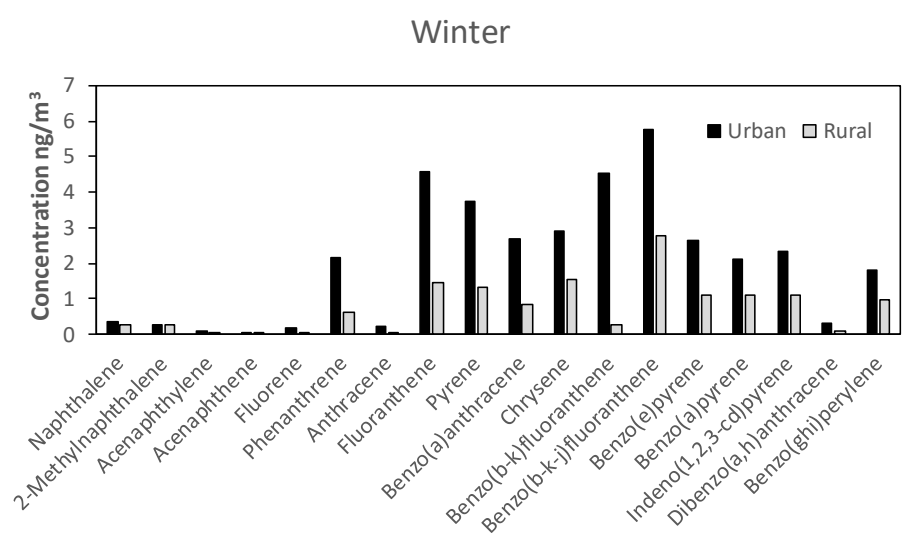

$\mathrm{a}$,

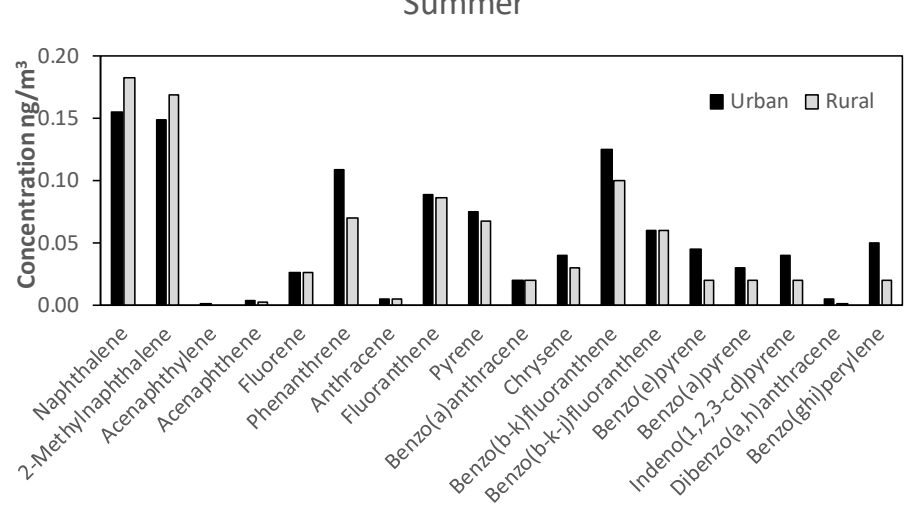

$\mathrm{c}$,

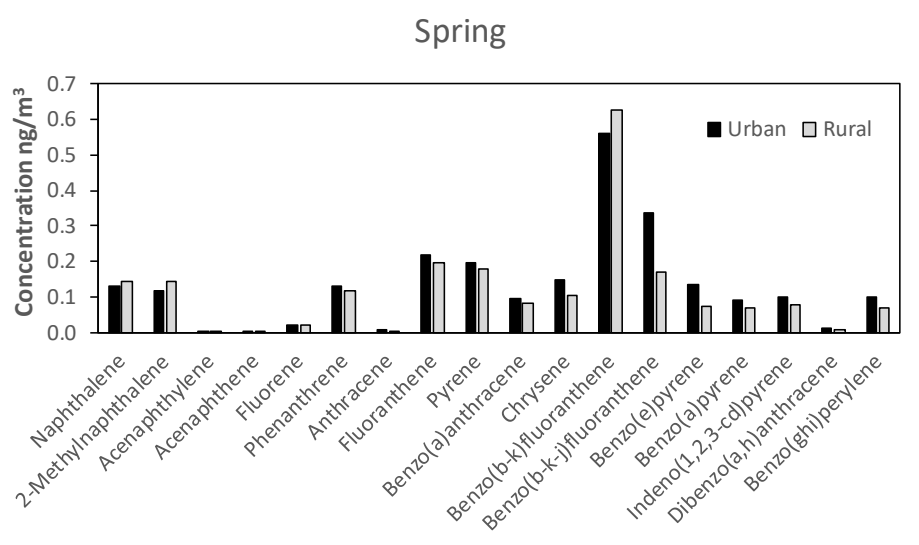

b,

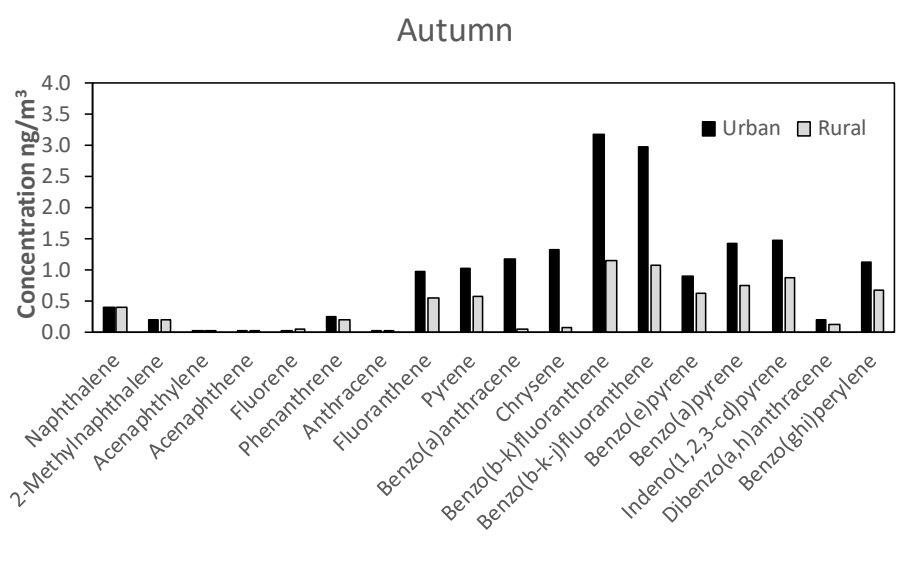

$\mathrm{d}$,

Fig. 4: Mean concentrations of individual PAHs associated to PM10 in urban site of Györ compared to rural site of Sarród in different seasons calculated from the all examined samples. (These data were obtained for the following sampling periods: B(b-k)F for 2008-2009; B(b-k-j)F for 2010-2014; BeP for 2011-2014; all of the other individual PAHs for 2008-2014).

\subsection{Concentrations of PAHs in Urban PM2.5 Aerosol Samples}

The concentrations of Total PAHs ranged from 1.32 to $37.27 \mathrm{ng} / \mathrm{m}^{3}$ with the mean value of $10.54 \mathrm{ng} / \mathrm{m}^{3}$ at the two urban sites, and on average accounted for $0.045 \%$ of the PM2.5 mass. Higher concentrations of PM2.5-bound Total PAHs were measured in November 2014 than associated to PM10 in October (Fig. 5), which can be explained by the time of heating season.

The HMW PAHs with 5 and 6 aromatic rings were the most abundant PAHs in PM2.5 aerosol samples, which averaged $82 \%$ of Total PAHs (Fig. 6). Acenaphthene and fluorene were not detected in the PM2.5 samples. The dominant PM2.5-bound PAH compounds were IND and sum of three BF isomers followed by benzo(ghi)perylene and BaP at both urban sites. However, higher PAH levels were observed at site U1 compared with U2. The BaP, which is regarded as the most toxic PAH component was detected in relatively high concentrations, and it was in $50 \%$ of the samples above the value of $1 \mathrm{ng} / \mathrm{m}^{3}$ defined for health protection. Only a relatively insignificant amount of LMW PAHs was found in the PM2.5 samples. Comparatively, the high fraction of MMW and HMW PAHs in Total PAHs indicate pyrogenic sources in all of the PM2.5 samples of Györ [7]. 


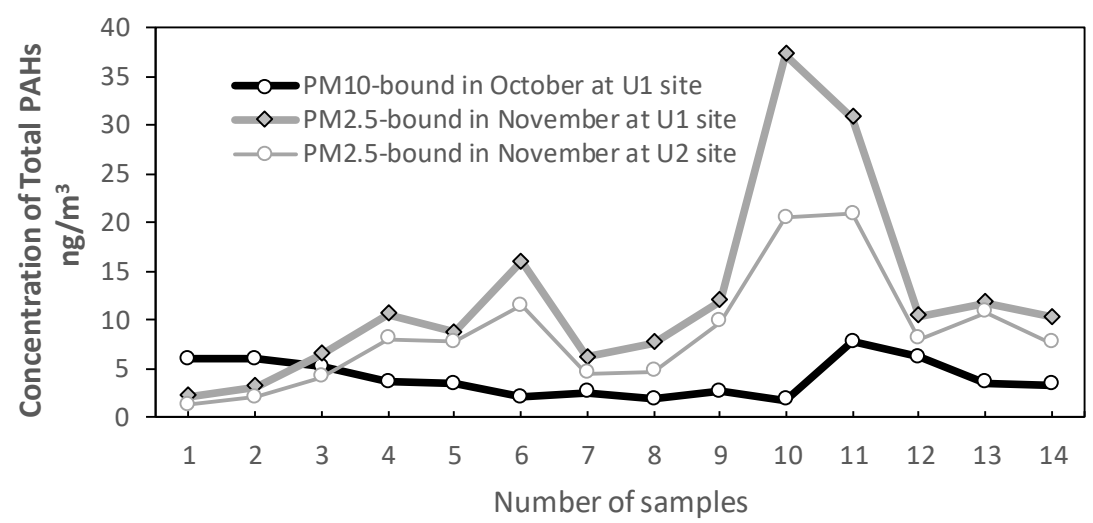

Fig. 5: Mean concentrations of Total PAHs associated to PM2.5 and PM10 in urban sites of Györ in a heating season.

Autumn

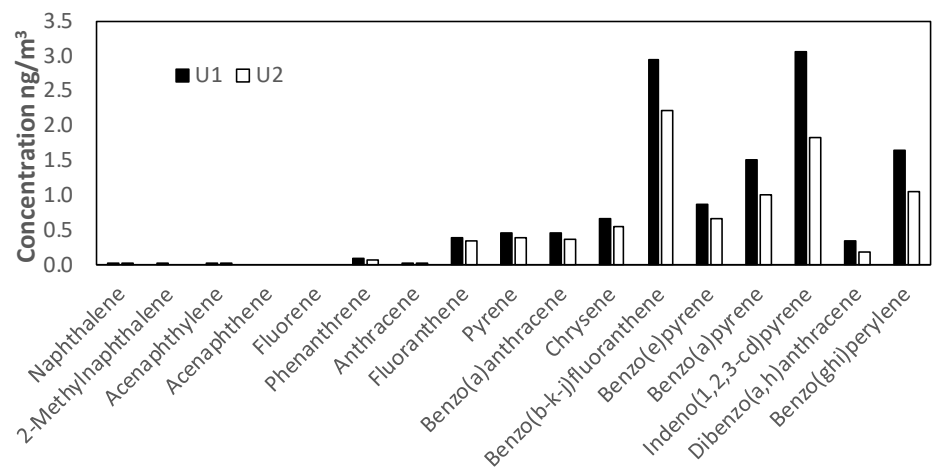

Fig. 6: Mean concentrations of individual PAHs associated to PM2.5 in urban sites of Győr in a heating season.

\subsection{Assessment of BaP-equivalent Carcinogenicity}

The mean BaP-equivalent concentrations, TEQ and LCR in this study are shown in Table 2. On average, about 27 and 18 times less TEQ values in PM10 in urban and rural sites were detected in the non-heating seasons than in the heating periods, respectively. Similarly to the Total PAHs concentrations, about 2 times higher mean TEQ value was obtained for urban samples compared to the rural samples. Relatively high mean TEQ concentration level were also observed for PM2.5-bound PAHs in the examined month.

The data of individual PAHs listed in Table 2 show that the largest contribution of individual PAHs to carcinogenic risk potential was the $\mathrm{BaP}$ in all seasons, accounting for about 50-65\%. It was observed that during winter and autumn, the estimated lung cancer risk exceeded the WHO health-based guideline $\left(8.7 \times 10^{-5}\right)$ in the urban and in rural areas. However, in spring or summer the LCR values were acceptable. 
Table 2: Mean BaP-equivalent concentrations and LCR values.

\begin{tabular}{|c|c|c|c|c|c|c|}
\hline \multirow{2}{*}{$\begin{array}{c}\text { Compound } \\
\mathrm{ng} / \mathrm{m}^{3}\end{array}$} & \multicolumn{5}{|c|}{$\begin{array}{l}\text { PM10-bound PAHs } \\
\quad(2008-2014)\end{array}$} & \multirow{2}{*}{$\begin{array}{l}\text { PM2.5-bound } \\
\text { PAHs } \\
(2014) \\
\text { Autumn }\end{array}$} \\
\hline & Winter & Spring & Summer & Autumn & $\begin{array}{c}\text { All } \\
\text { season }\end{array}$ & \\
\hline \multicolumn{7}{|l|}{ Urban area } \\
\hline Benzo(a)anthracene & 0.268 & 0.010 & 0.002 & 0.116 & 0.099 & 0.041 \\
\hline Benzo(a)pyrene & 2.190 & 0.090 & 0.030 & 1.410 & 0.930 & 1.250 \\
\hline Benzo(b-k-j)fluoranthene & 0.541 & 0.040 & 0.012 & 0.303 & 0.224 & 0.515 \\
\hline Benzo(ghi)perylene & 0.018 & 0.001 & 0.001 & 0.011 & 0.008 & 0.014 \\
\hline Chrysene & 0.029 & 0.002 & 0.0004 & 0.013 & 0.011 & 0.006 \\
\hline Dibenzo(a,h)anthracene & 0.300 & 0.010 & 0.004 & 0.190 & 0.126 & 0.260 \\
\hline Indeno(1,2,3-cd)pyrene & 0.235 & 0.010 & 0.004 & 0.148 & 0.099 & 0.244 \\
\hline TEQ ng/m $\mathbf{m}^{3}$ & 3.581 & 0.163 & 0.053 & 2.191 & 1.497 & 2.330 \\
\hline LCR & $3.12 \times 10^{-4}$ & $1.42 \times 10^{-5}$ & $4.61 \times 10^{-6}$ & $1.91 \times 10^{-4}$ & $1.30 \times 10^{-4}$ & $2.03 \times 10^{-4}$ \\
\hline \multicolumn{7}{|l|}{ Rural area } \\
\hline Benzo(a)anthracene & 0.084 & 0.005 & 0.002 & 0.004 & 0.024 & - \\
\hline Benzo(a)pyrene & 1.080 & 0.080 & 0.020 & 0.750 & 0.483 & - \\
\hline Benzo(b-k-j)fluoranthene & 0.304 & 0.020 & 0.007 & 0.172 & 0.126 & - \\
\hline Benzo(ghi)perylene & 0.001 & 0.0007 & 0.0002 & 0.007 & 0.002 & - \\
\hline Chrysene & 0.015 & 0.001 & 0.0003 & 0.001 & 0.004 & - \\
\hline Dibenzo(a,h)anthracene & 0.101 & 0.006 & 0.001 & 0.105 & 0.053 & - \\
\hline Indeno(1,2,3-cd)pyrene & 0.110 & 0.008 & 0.002 & 0.087 & 0.052 & - \\
\hline TEQ ng/m ${ }^{3}$ & 1.695 & 0.121 & $\mathbf{0 . 0 3 3}$ & 1.126 & 0.743 & - \\
\hline LCR & $1.47 \times 10^{-4}$ & $1.05 \times 10^{-5}$ & $2.87 \times 10^{-6}$ & $9.80 \times 10^{-5}$ & $6.46 \times 10^{-5}$ & - \\
\hline
\end{tabular}

\section{Conclusion}

Based on 7 years PM10-bound PAH monitoring data, it was found that significantly higher concentrations of PAHs were detected in samples collected in the heating seasons compared with spring and summer. About 2 times higher total PAHs concentrations were obtained for urban samples compared to the rural samples on average. The calculated TEQ and LCR values in this study were also revealed that the local population appeared to be exposed to significantly higher cancer risk with PAHs in the heating seasons. However, it should be noted that the risk estimates presented are very uncertain, and could be understood only as a crude estimation of cancer risk from the PAH inhalation.

The results of PM2.5-bound PAHs monitoring carried out in a heating season showed that the PAH compounds could detected as well as in PM10 aerosol samples. Relatively high concentration levels were observed for PM2.5-bound PAHs in the examined late autumn period. It can be suggested that future air quality studies should also include analysis of seasonal distribution of PM2.5-bound PAHs. Simultaneous analysis of PM10 and PM2.5 samples would also be recommended.

\section{Acknowledgements}

This work was supported by the ÚNKP-17-4 New National Excellence Program of the Ministry of Human Capacities. We are grateful for the chemical analysis, monitoring data and site information of our cooperation group members (especially József Erdős and István Vass) in Government Office for Győr-
Moson-Sopron County, the Environmental Protection Laboratory (Györ, Hungary).

\section{References}

[1] K. Ravindra, R. Sokhi and R. Van Grieken, "Atmospheric polycyclic aromatic hydrocarbons: source attribution, emission factors and regulation,” Atmos. Environ., vol. 42, no. 13, pp. 2895-2921, 2008.

[2] K. Srogi, "Monitoring of environmental exposure to polycyclic aromatic hydrocarbons: a review," Environmental Chem. Lett., vol. 5, no. 4, 169-195, 2007. 
[3] EEA, “Air quality in Europe - 2015 Report,” European Environment Agency, Luxembourg, 2015.

[4] L. H. Keith, "The source of U.S. EPA's sixteen PAH priority pollutants," Polycyc. Aromat. Compd., vol. 35, no. 2-4, pp. 147-160, 2015.

[5] C. B. B. Guerreiro, J. Horalek, F. de Leeuw and F. Couvidat, "Benzo(a)pyrene in Europe: Ambient air concentrations, population exposure and health effects," Atmos. Environ., vol. 43, pp. 4187-4193, 2009.

[6] OMSZ ÉLFO, "Summary of the OLM PM10 sampling program in 2012," Reference Centre for Air Quality Protection, Budapest, 2013. (in Hungarian)

[7] A. S. Nagy and J. Szabó, "Characterization of PM2.5-bound polycyclic aromatic hydrocarbons in the ambient air of Győr, Hungary," Polycyc. Aromat. Compd., 2017. [Online].

[8] J. Szabó, A. S. Nagy and J. Erdős, "Ambient concentrations of PM10, PM10-bound polycyclic aromatic hydrocarbons and heavy metals in an urban site of Györ, Hungary," Air Qual. Atmos. Health, vol. 8, no. 2, pp. 229241, 2015.

[9] MSZ EN 15549:2008, "Air quality - standard method for measurement of the concentration of benzo(a)pyrene in ambient air," Hungarian Standard Association, Budapest, 2008.

[10] A. S. Nagy, J. Szabó and I. Vass, "Occurrence and distribution of polycyclic aromatic hydrocarbons in surface water of the Raba River, Hungary," J. Environ. Sci. Health A Tox. Hazard. Subst. Environ. Eng., vol. 48, no. 10, pp. 11901200, 2013.

[11] ALS, "Benzo(a)pyrene toxic equivalence quotient (TEQ) and aggregate organochlorine pesticides parameters," EnviroMail No. 59 Re-Release, July, 2013.

[12] N. O. Alvesa, J. Brito, S. Caumo, A. Arana, S. S. Hacon, P. Artaxo, R. Hillamo, K. Teinilä, S. R. B. Medeiros and P. C. Vasconcellos, "Biomass burning in the Amazon region: aerosol source apportionment and associated health risk assessment," Atmos. Environ., vol. 120, pp. 277-285, 2015.

[13] Z. Li, E. N. Porter, A. Sjödin, L. L. Needham, S. Lee, A. G. Russell and J. A. Mulholland, "Characterization of PM2.5-bound polycyclic aromatic hydrocarbons in Atlanta - seasonal variations at urban, suburban, and rural ambient air monitoring sites," Atmos. Environ., vol. 43, no. 27, pp. 4187-4193, 2009. 